\title{
Article
}

\section{Ortho Isomeric Mn(III) N-Alkyl- and Alkoxyalkylpyridylporphyrins-Enhancers of Hyaluronan Degradation Induced by Ascorbate and Cupric Ions ${ }^{\dagger}$}

\author{
Katarína Valachová ${ }^{1, *(\mathbb{D})}$, Peter Rapta ${ }^{2, * \mathbb{D}}$, Nuno M. M. Moura ${ }^{3} \mathbb{D}$, Ines Batinic-Haberle ${ }^{4}$ and Ladislav Šoltés ${ }^{1}$ \\ 1 Centre of Experimental Medicine, Institute of Experimental Pharmacology and Toxicology, \\ Slovak Academy of Sciences, Dúbravská cesta 9, SK-841 04 Bratislava, Slovakia; exfasolt@savba.sk \\ 2 Institute of Physical Chemistry and Chemical Physics, Slovak University of Technology in Bratislava, \\ Radlinského 9, SK-812 37 Bratislava, Slovakia \\ 3 LAQV-REQUIMTE, Department of Chemistry, University of Aveiro, 3810-193 Aveiro, Portugal; \\ nmoura@ua.pt \\ 4 Department of Radiation Oncology, Duke University School of Medicine, Durham, NC 27710, USA; \\ ibatinic@duke.edu \\ * Correspondence: katarina.valachova@savba.sk (K.V.); peter.rapta@stuba.sk (P.R.) \\ † In memoriam to Professor Robert Stern.
}

check for updates

Citation: Valachová, K.; Rapta, P.; Moura, N.M.M.; Batinic-Haberle, I.; Šoltés, L. Ortho Isomeric Mn(III) N-Alkyl- and Alkoxyalkylpyridylporphyrins-Enhancers of Hyaluronan Degradation Induced by Ascorbate and Cupric Ions. Int. J. Mol. Sci. 2021, 22, 8608. https://doi.org/ $10.3390 /$ ijms 22168608

Academic Editor: Diego Guidolin

Received: 23 June 2021

Accepted: 6 August 2021

Published: 10 August 2021

Publisher's Note: MDPI stays neutral with regard to jurisdictional claims in published maps and institutional affiliations.

Copyright: (c) 2021 by the authors. Licensee MDPI, Basel, Switzerland. This article is an open access article distributed under the terms and conditions of the Creative Commons Attribution (CC BY) license (https:/ / creativecommons.org/licenses/by/ $4.0 /)$.

\begin{abstract}
High levels of hyaluronic acid (HA) in tumors correlate with poor outcomes with several types of cancers due to HA-driven support of adhesion, migration and proliferation of cells. In this study we explored how to enhance the degradation of HA into low-molecular fragments, which cannot prevent the immune system to fight tumor proliferation and metastases. The physiological solution of HA was exposed to oxidative degradation by ascorbate and cupric ions in the presence of either one of three ortho isomeric Mn(III) substituted $N$-alkyl- and alkoxyalkylpyridylporphyrins or para isomeric $\mathrm{Mn}$ (III) $\mathrm{N}$-methylpyridyl analog, commonly known as mimics of superoxide dismutase. The changes in hyaluronan degradation kinetics by four Mn(III) porphyrins were monitored by measuring the alteration in the dynamic viscosity of the HA solution. The ortho compounds MnTE-2$\mathrm{PyP}^{5+}$ (BMX-010, AEOL10113), MnTnBuOE-2-PyP ${ }^{5+}$ (BMX-001) and MnTnHex-2-PyP ${ }^{5+}$ are able to redox cycle with ascorbate whereby producing $\mathrm{H}_{2} \mathrm{O}_{2}$ which is subsequently coupled with $\mathrm{Cu}(\mathrm{I})$ to produce the ${ }^{\bullet} \mathrm{OH}$ radical essential for HA degradation. Conversely, with the para analog, MnTM-4$\mathrm{PyP}^{5+}$, no catalysis of HA degradation was demonstrated, due to its inertness towards redox cycling with ascorbate. The impact of different Mn(III)-porphyrins on the HA decay was further clarified by electron paramagnetic resonance spectrometry. The ability to catalyze the degradation of HA in a biological milieu, in the presence of cupric ions and ascorbate under the conditions of high tumor oxidative stress provides further insight into the anticancer potential of redox-active ortho isomeric Mn(III) porphyrins.
\end{abstract}

Keywords: SOD mimics; Mn porphyrins; hyaluronic acid degradation; ascorbate/copper; relevance to cancer; ROS production

\section{Introduction}

$\mathrm{Mn}(\mathrm{III})$ cationic ortho substituted $\mathrm{N}$-alkyl- and alkoxyalkylpyridylporphyrins (MnPs) were initially designed as superoxide dismutase mimics, i.e., the catalysts of $\mathrm{O}_{2}{ }^{\bullet-}$ dismutation. As the knowledge of their chemistry increased along with the rising knowledge of redox biology of a cell, it became obvious that such compounds undergo diverse reactions in biological systems and carry large therapeutic potential [1,2]. Two compounds, Mn(III) meso-tetrakis(N-ethylpyridinium-2-yl)porphyrin, MnTE-2-PyP ${ }^{5+}$ (AEOL10113, BMX-010) and $\mathrm{Mn}(\mathrm{III})$ meso-tetrakis(N-butoxyethylpyridinium-2-yl) porphyrin, MnTnBuOE-2-PyP $\mathrm{P}^{5+}$ (BMX-001, Figure 1) are now in five phase two clinical trials [1,3]. Most of the potent 
superoxide dismutase (SOD) mimics have $\mathrm{Mn}$ in a +3 oxidation state. Such a state is stabilized by the porphyrin macrocyclic ring, which also assures the integrity of the Mn center, preventing its loss from the porphyrin ligand [1]. Based on the favorable redox properties, we aim here to see if MnTE-2-PyP ${ }^{5+}$ and MnTnBuOE-2-PyP ${ }^{5+}$, as well as Mn(III) mesotetrakis( $\mathrm{N}$-n-hexylpyridinium-2-yl)porphyrin, $\mathrm{MnTnHex}-2-\mathrm{PyP}^{5+}$, can assist $\mathrm{Cu}$ /ascorbate system in degrading high-molar-mass hyaluronic acid (HA). We compared these ortho (2) isomers to a para (4) isomer, $\mathrm{Mn}(\mathrm{III})$ meso-tetrakis(N-methylpyridinium-4-yl)porphyrin, MnTM-4-PyP ${ }^{5+}$ (Figure 1). Relative to ortho isomers, MnTM-4-PyP $\mathrm{P}^{5+}$ compound is stabilized in a +3 oxidation state, and cannot be easily reduced with cellular reductants due to its more than $160 \mathrm{mV}$ negative metal-centered reduction potential for $\mathrm{Mn}$ (III)/Mn(II) redox couple, $E_{1 / 2}=+60 \mathrm{mV}$ vs. NHE when compared to ortho analogs [3,4]. Namely, the MnTE-2-PyP ${ }^{5+}$ and MnTnBuOE-2-PyP ${ }^{5+}$ have $E_{1 / 2}$ of $+228 \mathrm{mV}$ vs. NHE and $+277 \mathrm{mV}$ vs. NHE for $\mathrm{Mn}(\mathrm{III}) / \mathrm{Mn}(\mathrm{II})$ redox couples, respectively, [1]. Due to inferior redox properties, MnTM-4-PyP ${ }^{5+}$ cannot be readily reduced with ascorbate in order to become oxidized with oxygen in the second step to produce $\mathrm{O}_{2}{ }^{\bullet-}$ and, subsequently, (enzymatically or via self-dismutation) $\mathrm{H}_{2} \mathrm{O}_{2}$. While the mechanism of the catalysis of $\mathrm{O}_{2}{ }^{\bullet-}$ dismutation by ortho isomers and para MnTM-4-PyP ${ }^{5+}$ is identical, the thermodynamic yields controlled by their reduction potentials are different. Importantly, ortho compounds are bulky and more so those with long hexyl and butoxyethyl lipophilic chains. Para isomer with short methyl chains, MnTM-4-PyP ${ }^{5+}$, is planar and that facilitates its interactions with biomolecules such as intercalation into nucleic acids, which results in the loss of its SOD-like activity [5].
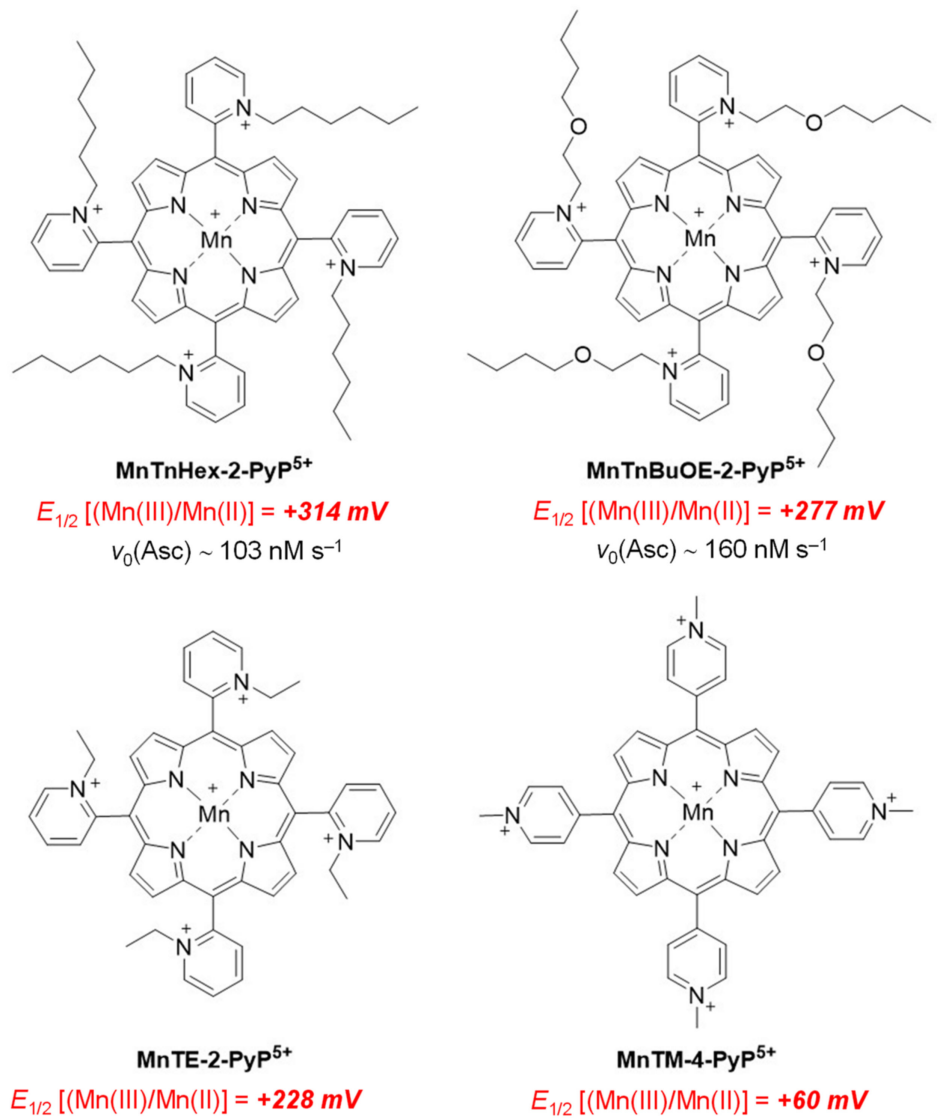

$$
\begin{gathered}
\text { MnTE-2-PyP }{ }^{5+} \\
E_{1 / 2}[(\mathrm{Mn}(\mathrm{III}) / \mathrm{Mn}(\mathrm{II})]=+228 \mathrm{mV} \\
V_{0}(\mathrm{Asc}) \sim 286 \mathrm{nM} \mathrm{s}^{-1} \\
E_{1 / 2}[(\mathrm{O}=\mathrm{Mn}(\mathrm{IV}) / \mathrm{Mn}(\mathrm{III})] \sim+540 \mathrm{mV} \\
k_{\text {red }}[\mathrm{O}=\mathrm{Mn}(\mathrm{IV}) \mathrm{P}]=3.5 \times 10^{7} \mathrm{M}^{-1} \mathrm{~s}^{-1}
\end{gathered}
$$

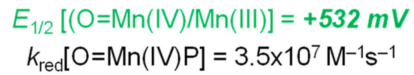

Figure 1. Chemical structures of redox-active cationic $\mathrm{Mn}(\mathrm{III})$ porphyrins and the reduction potentials, $E_{1 / 2}$ vs. NHE for $\mathrm{Mn}^{\mathrm{III}} / \mathrm{Mn}^{\mathrm{II}}$ (in red) and $\mathrm{O}=\mathrm{Mn}^{\mathrm{IV}} / \mathrm{Mn}^{\mathrm{III}}$ (in green, measured at $\mathrm{pH} 11$ ) redox couples [6,7]. The values shown for the $k_{\text {red }}$ and $E_{1 / 2}[(\mathrm{O}=\mathrm{Mn}(\mathrm{IV}) / \mathrm{Mn}(\mathrm{III})]$ for the ortho analog, 
MnTE-2-PyP ${ }^{5+}$, are based on the reported values [6] for the methyl analog, MnTM-2-PyP ${ }^{5+}$. We may safely assume that those values for methyl and ethyl analogs are similar based on the fact that kinetic and thermodynamic values reported thus far for the methyl and ethyl analogs are similar, if not identical [7]. Values for $\mathrm{pH} 11$ are shown to indicate that $E_{1 / 2}$ values are identical for all isomers. The values for $\mathrm{O}=\mathrm{Mn}(\mathrm{IV}) / \mathrm{Mn}(\mathrm{III})$ couple were obtained in the whole range of $\mathrm{pH}$ only for MnTE-2-PyP [8] and at $\mathrm{pH}=7$ it is $+517 \mathrm{mV}$ vs. NHE [2]. Additionally, the initial ascorbate oxidation rates, $v_{0}(\mathrm{Asc})$, which relate to the ability of Mn porphyrins to oxidize ascorbate to ascorbyl radical employing $\mathrm{Mn}^{\mathrm{III}} / \mathrm{Mn}^{\mathrm{II}}$ redox couple were reported in [1], and the second order rate constants $k_{\text {red }}[\mathrm{O}=\mathrm{Mn}(\mathrm{IV}) \mathrm{P}]$ at $37^{\circ} \mathrm{C}$ for the reduction of the high valent oxo $\mathrm{Mn}(\mathrm{IV})$ state by ascorbate were reported in [6].

Ascorbic acid $\left(\mathrm{AscH}_{2}\right)$ - vitamin $\mathrm{C}$-is an essential nutritional component for humans [9]. At physiological $\mathrm{pH}$, ascorbic acid is in monodeprotonated form, $\mathrm{AscH}^{-}$. In vivo, besides other physiological functions, ascorbate acts as an antioxidant; one of its major roles, in concert with tocopherol, is the protection of the lipid membranes against peroxidation. Yet, in the presence of transition metals such as $\mathrm{Cu}$ and $\mathrm{Fe}$, ascorbate becomes involved in oxidative processes. Under aerobic physiological conditions, ascorbate can reduce $\mathrm{Cu}$ (II) to $\mathrm{Cu}(\mathrm{I})$ while being oxidized to ascorbyl radical, $\mathrm{HAsc}^{\bullet}[10]$. $\mathrm{Cu}(\mathrm{I})$ subsequently reacts with $\mathrm{H}_{2} \mathrm{O}_{2}$, producing hydroxyl radicals while it becomes reoxidized/regenerated into $\mathrm{Cu}(\mathrm{II})$, closing a catalytic cycle; the catalysis continues as long as ascorbate and oxygen are available.

The system is known as Weissberger's biogenic oxidative system (WBOS) [11] and is reportedly one of the most effective generators of ${ }^{\bullet} \mathrm{OH}$ radicals, which are responsible for the destruction of DNA, RNA, proteins, lipids, and polysaccharides in living organisms [12]. Such an ${ }^{\bullet} \mathrm{OH}$-generating system may be employed in exploring the antioxidative efficacy of natural or synthetic compounds for therapeutic and industrial purposes [11,13].

On the outer surface of the cell, mammalian cells have a highly specific glycocalyx, which is non-immunogenic for components of the immune system. We can assume that glycocalyx of the cancer cells, including the metastatic ones, is somewhat different from that of normal cells $[14,15]$. Consequently, a different glycocalyx in metastatic and cancer cells could become immunogenic [16]. However, the reported data show that the surface of the cancer cells is populated with CD44 receptors, which tightly bind high-molar-mass hyaluronic acid extruding from cells [17]. Consequently, the cancer cell, enveloped with non-immunogenic high-molar-mass HA, cannot be recognized by the immune system.

Therefore, our attention has been focused on developing strategies to destruct the "invisibile" coat of the cancer cells by radical-based HA degradation, using WBOS further enforced by MnPs. This should lead to the effective shortening of the long chains of HA macromolecule towards the formation of the fragments of low-molecular HA mass. Such fragments would become immunogenic, attracting components of the immune system to reach the surface of the cancer cell, recognize a foreign glycocalyx and in turn, destruct both cancer and metastatic cells.

In this manuscript we investigate the oxidative degradation of HA catalyzed by $\mathrm{Mn}$ porphyrins in the presence of $\mathrm{Cu}(\mathrm{II})$ and ascorbate, using three ortho isomeric cationic $\mathrm{Mn}$

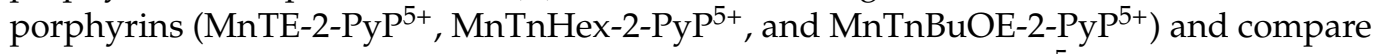
them to the efficacy of the less redox active para isomer, MnTM-4-PyP $\mathrm{P}^{5+}$. A general scheme of their action in the presence of WBOS is proposed. Different behavior of investigated Mn complexes-which can act as catalysts of HA oxidative degradation as well as scavengers of alkoxy-/peroxy type HA macroradicals-is discussed.

\section{Results and Discussion}

When the HA was subjected to oxidative degradation by $1 \mu \mathrm{M} \mathrm{Cu}(\mathrm{II})$ and $100 \mu \mathrm{M}$ ascorbate, significant degradation of $\mathrm{HA}$ macromolecules by ${ }^{\circ} \mathrm{OH}$ radicals was observed (Figure 2A, black curve, the reference). The addition of $\mathrm{MnTE}^{-2-\mathrm{PyP}^{5+}}$ at concentrations of $0,5,20$ and $100 \mu \mathrm{M}$ resulted in dose-dependent enhancement of HA degradation. The 
highest rate of HA degradation occurred within $30 \mathrm{~min}$ and at $100 \mu \mathrm{M} \mathrm{MnP}$ and was subsequently slowed down due to the consumption of oxygen and ascorbate (Figure 2A, cyan curve).
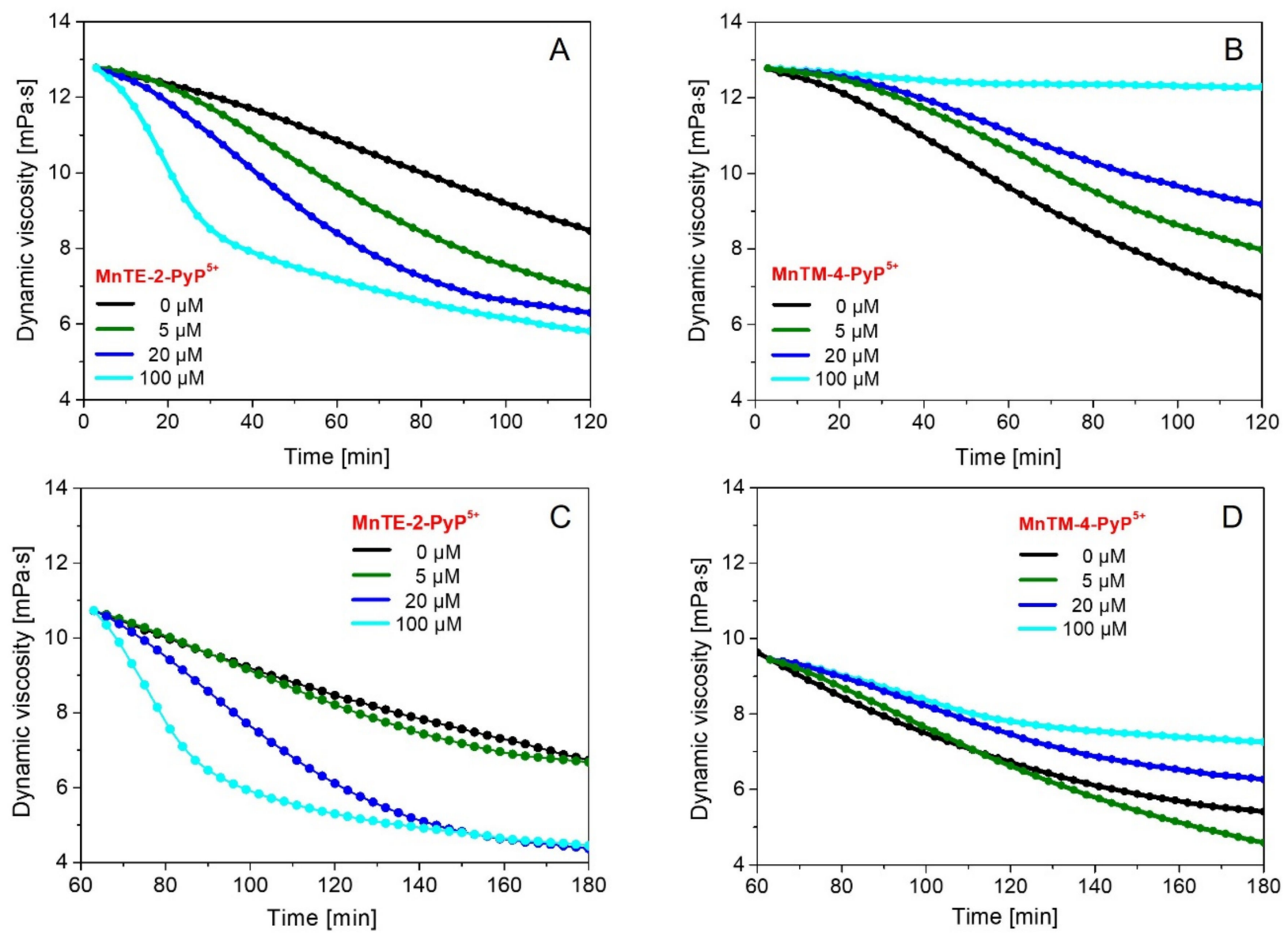

Figure 2. Time-dependent changes in dynamic viscosity of the HA solution subjected to $1 \mu \mathrm{M} \mathrm{Cu}(\mathrm{II})$ and $100 \mu \mathrm{M}$ ascorbate in the presence of $(\mathbf{A}) \mathrm{MnTE}_{2}-\mathrm{PyP}^{5+}$ or (B) MnTM-4-PyP $\mathrm{P}^{5+}$ at different concentrations: 0 (black curve), 5 (green curve), 20 (blue curve), and $100 \mu \mathrm{M}$ (cyan curve). The concentration of HA was $1.75 \mathrm{mg} / \mathrm{mL}$. Panel (C)-MnTE-2-PyP ${ }^{5+}$ was added at $^{-}$ $1 \mathrm{~h}$ after HA degradation began. Panel (D)-MnTM-4-PyP ${ }^{5+}$ was added at $1 \mathrm{~h}$ after HA degradation began.

When MnTE-2-PyP $\mathrm{P}^{5+}$ was added to the HA reaction mixture at 20 and $100 \mu \mathrm{M}$ (but not at low $5 \mu \mathrm{M}$ concentration) at $1 \mathrm{~h}$ after the production of alkoxy-/peroxy-type radicals was already established [18], again a large rate of HA degradation was initially observed and was subsequently reduced due to the consumption of oxygen and ascorbate (see Figure 2C, blue and cyan curve, respectively). The increased degradation of HA may be due to the reduction of $\mathrm{MnP}$ with ascorbate, but also to the reaction of Mn porphyrins with peroxyand alkoxy-type radicals, producing high-valent and highly oxidizing $\mathrm{Mn}(\mathrm{IV})$ and $\mathrm{Mn}(\mathrm{V})$ oxo species. These high-valent oxo species may undergo reduction with ascorbate and could enhance the HA degradation.

However, with the para isomer, MnTM-4-PyP ${ }^{5+}$, we observed a different behavior (Figure 2B). When used at $100 \mu \mathrm{M}$ (where MnTE-2-PyP ${ }^{5+}$ is the most potent enhancer of HA degradation), no HA degradation was demonstrated (see Figure 2B, cyan curve). HA degradation was inhibited to a lower degree in the presence of $20 \mu \mathrm{M} \mathrm{MnTM}-4-\mathrm{PyP}^{5+}$ (blue curve), and more so in $5 \mu \mathrm{M}$ MnTM-4-PyP ${ }^{5+}$ (green curve). We explain such data with the differences in the $\mathrm{MnP} /$ ascorbate ratio. When the ratio was 1 , no reduction of $\mathrm{Mn}^{\text {III }} \mathrm{P}^{5+}$ with ascorbate happened; in turn, no reoxidation of $\mathrm{Mn}^{\mathrm{II}} \mathrm{P}^{4+}$ occurred that would have given rise to $\mathrm{O}_{2}{ }^{\bullet-}$ and subsequently $\mathrm{H}_{2} \mathrm{O}_{2}$. However, when ascorbate is in 5 or 20-fold excess over MnP, the reduction of MnTM-4-PyP ${ }^{5+}$ with ascorbate becomes thermodynam- 
ically permissible, apparently giving rise to lower inhibition of HA degradation. The corresponding initial rates, $-(\mathrm{d} \eta / \mathrm{d} t)_{t=0}$, are listed in Table 1 .

Table 1. The values of initial rates of HA degradation, derived from the time-dependent changes in dynamic viscosity $(\eta)$ of the HA solution subjected to MnTE-2-PyP $\mathrm{P}^{5+}$ or MnTM-4-PyP $\mathrm{P}^{5+}$ at different concentrations and $100 \mu \mathrm{M}$ ascorbate in the in the presence of $1 \mu \mathrm{M} \mathrm{Cu}(\mathrm{II})$. Initial rates $-(\mathrm{d} \eta / \mathrm{d} t)_{t=0}$ : were listed where Mn porphyrins were added at the start of HA degradation; rates $-(\mathrm{d} \eta / \mathrm{d} t)_{t=60}$ : Mn porphyrins were added after $60 \mathrm{~min}$ of HA degradation.

\begin{tabular}{|c|c|c|c|c|}
\hline Mn Complex & $0 \mu \mathbf{M}$ & $5 \mu \mathrm{M}$ & $20 \mu \mathrm{M}$ & $100 \mu \mathrm{M}$ \\
\hline \multicolumn{5}{|c|}{ Initial rates $-(\mathrm{d} \eta / \mathrm{d} t)_{t=0} / \mathrm{mPa} \cdot \mathrm{s} \cdot \mathrm{min}^{-1}$} \\
\hline MnTE-2-PyP $5+$ & 0.0209 & 0.0244 & 0.0434 & 0.0954 \\
\hline MnTM-4-PyP $\mathrm{P}^{5+}$ & 0.0311 & 0.0163 & 0.0085 & 0.0074 \\
\hline \multicolumn{5}{|c|}{ Rates at $t=60 \mathrm{~min},-(\mathrm{d} \eta / \mathrm{d} t)_{t=60} / \mathrm{mPa} \cdot \mathrm{s} \cdot \mathrm{min}^{-1}$} \\
\hline MnTE-2-PyP $5+$ & 0.0354 & 0.0354 & 0.0597 & 0.1282 \\
\hline MnTM-4-PyP ${ }^{5+}$ & 0.0597 & 0.0401 & 0.0190 & 0.0190 \\
\hline
\end{tabular}

In conclusion, due to the lack of $\mathrm{Mn}$ (III)/Mn(II) redox cycling with ascorbate and thus to the lack of $\mathrm{H}_{2} \mathrm{O}_{2}$ production essential for HA degradation, the para MnTM-4-PyP ${ }^{5+}$ is an inefficient catalyst. Regardless of the time when $\mathrm{MnP}$ was added into the reaction mixture, the data point to the critical role the reduction of $\mathrm{Mn}^{\mathrm{III}} \mathrm{P}^{5+}$ with ascorbate plays, as its subsequent reoxidation is accompanied with the production of $\mathrm{H}_{2} \mathrm{O}_{2}$.

Additionally, we compared activity of four investigated $\mathrm{Mn}$ porphyrins at two time points in Figure 3: $60 \mathrm{~min}$ (left panel) and $120 \mathrm{~min}$ (right panel). The dose-dependent HA degradation at $60 \mathrm{~min}$ was seen with $\mathrm{MnTE}^{2}-\mathrm{PyP}^{5+}$ (triangle) and $\mathrm{MnTnHex}-2-\mathrm{PyP}^{5+}$ (star), but not with MnTnBuOE-2-PyP $\mathrm{P}^{5+}$ (circle). The fastest degradation of HA occurred at the concentration of $5 \mu \mathrm{M}$, where the large excess of ascorbate over $\mathrm{MnP}$ favored the reduction of $\mathrm{MnP}$. The three ortho isomeric $\mathrm{Mn}(\mathrm{III}) \mathrm{Ps}$ are easily reducible with ascorbate. When cycling back to $\mathrm{Mn}(\mathrm{III}) \mathrm{P}$ with oxygen, these MnPs would give rise to $\mathrm{H}_{2} \mathrm{O}_{2}$ which in turn would react with $\mathrm{Cu}(\mathrm{I})$ to make the hydroxyl radical. MnTM-4-PyP ${ }^{5+}$ (diamond), however, cannot be easily reduced with ascorbate $\left(E_{1 / 2}\left(\mathrm{Asc}^{\bullet-}, \mathrm{H}^{+} / \mathrm{AscH}^{-}\right)=+282 \mathrm{mV}\right.$ vs. NHE) unless ascorbate is in excess. Thus MnTM-4-PyP ${ }^{5+}$ and ascorbate cannot contribute to the hydroxyl radical production via reoxidation with oxygen to the same extent as ortho analogs do. MnTE-2-PyP $\mathrm{P}^{5+}$ (triangle) is the most potent promoter of alkoxy-/peroxytype-induced HA degradation at 120 min (Figure 3, right panel). Under these conditions, dose-dependence was seen also with both MnTnBuOE-2-PyP ${ }^{5+}$ (circle) and MnTnHex-2$\mathrm{PyP}^{5+}$ (star). In the presence of MnTnHex-2-PyP ${ }^{5+}$ (star), the rate of HA degradation was lower than the rate obtained in the presence of the two other complexes.

The long alkyl chains impose steric hindrance towards the reaction with ascorbate. While MnTnBuOE-2-PyP ${ }^{5+}$ has equally long pyridyl substituents as MnTnHex-2-PyP ${ }^{5+}$, the oxygen atoms facilitate the approach of ascorbate to the Mn center, presumably via hydrogen bonding between the oxygen atoms of butoxyethyl groups and the hydrogen atoms of ascorbate. In turn, it is a better catalyst of ascorbate oxidation. The ascorbate oxidation rate, $v_{0}=103 \mathrm{nM} \mathrm{s}^{-1}$, is the lowest for MnTnHex-2-PyP ${ }^{5+}$, followed by $v_{0}=160 \mathrm{nM} \mathrm{s}^{-1}$ for MnTnBuOE-2-PyP ${ }^{5+}$ and $v_{0}=286 \mathrm{nM} \mathrm{s}^{-1}$ for MnTE-2-PyP ${ }^{5+}[1,19]$. 

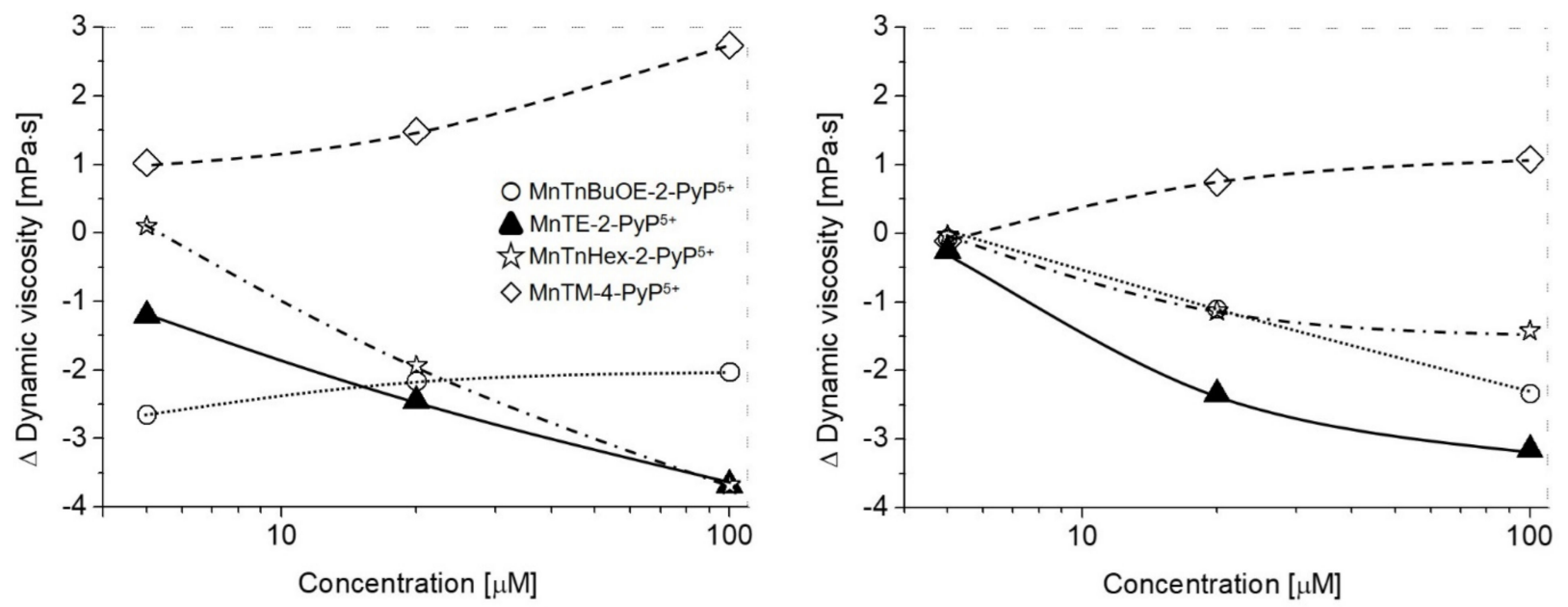

Figure 3. Concentration-dependent changes in dynamic viscosity of HA solutions exposed to oxidative degradation by $\mathrm{Cu}(\mathrm{II})$ $(1 \mu \mathrm{M})$ and ascorbic acid $(100 \mu \mathrm{M})$ in the presence of MnTnBuOE-2-PyP ${ }^{5+}$ (circles, dotted lines), MnTE-2-PyP ${ }^{5+}$ (triangles, solid lines), MnTnHex-2-PyP ${ }^{5+}$ (stars, dash-dotted lines) or MnTM-4-PyP ${ }^{5+}$ (diamond, dashed lines) at concentrations of 5, 20 and $100 \mu \mathrm{M}$. The concentration of HA was $1.75 \mathrm{mg} / \mathrm{mL}$. Left panel-MnPs were added to the HA mixture before initiating HA degradation. The $60 \mathrm{~min}$ data are shown. Right panel-MnPs were added to the HA mixture $1 \mathrm{~h}$ later. The 120 min data are shown.

EPR spectroscopy using a spin trapping technique was applied to prove the proposed reaction mechanism, as shown in Figures 4 and 5. For the reaction system (in the absence of HA) containing MnTE-2-PyP ${ }^{5+}$ and ascorbate, a low level of reactive radicals was detected in aqueous solutions in the presence of 5,5-dimethyl-1-pyrroline $N$-oxide (DMPO, black

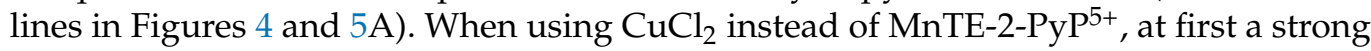
increase in ascorbyl radical was observed, which was followed by a continuous slight increase in ${ }^{\bullet} \mathrm{DMPO}-\mathrm{OH}$ adducts (red lines in Figures 4 and 5B).
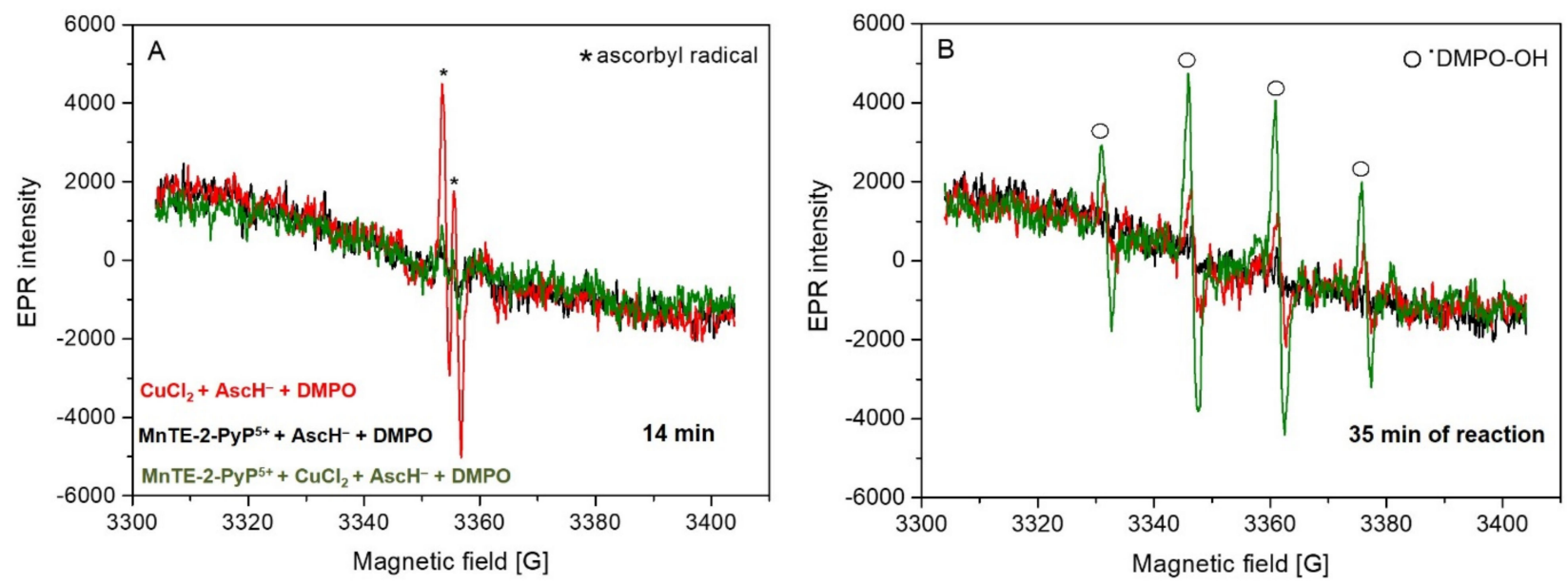

Figure 4. EPR spectra monitored after (A) $14 \mathrm{~min}$ and (B) $35 \mathrm{~min}$ of reaction in the aqueous solutions saturated with oxygen at room temperature for the following systems: System 1 (black traces): $7.5 \mu \mathrm{M} \mathrm{MnTE}-2-\mathrm{PyP}^{5+}+0.75 \mathrm{mM} \mathrm{AscH}^{-}+$ $0.053 \mathrm{M}$ DMPO; System 2 (red traces): $7.5 \mu \mathrm{M} \mathrm{CuCl}_{2}+0.75 \mathrm{mM} \mathrm{AscH}{ }^{-}+0.053 \mathrm{M}$ DMPO; System 3 (green traces): $7.5 \mu \mathrm{M}$ MnTE-2-PyP $\left.{ }^{5+}+7.5 \mu \mathrm{M} \mathrm{CuCl}_{2}+0.75 \mathrm{mM} \mathrm{AscH}^{-}+0.053 \mathrm{M} \mathrm{DMPO}\right) ;\left({ }^{*}\right.$-ascorbyl radical, $\bigcirc-\bullet$ DMPO-OH adduct $)$. 

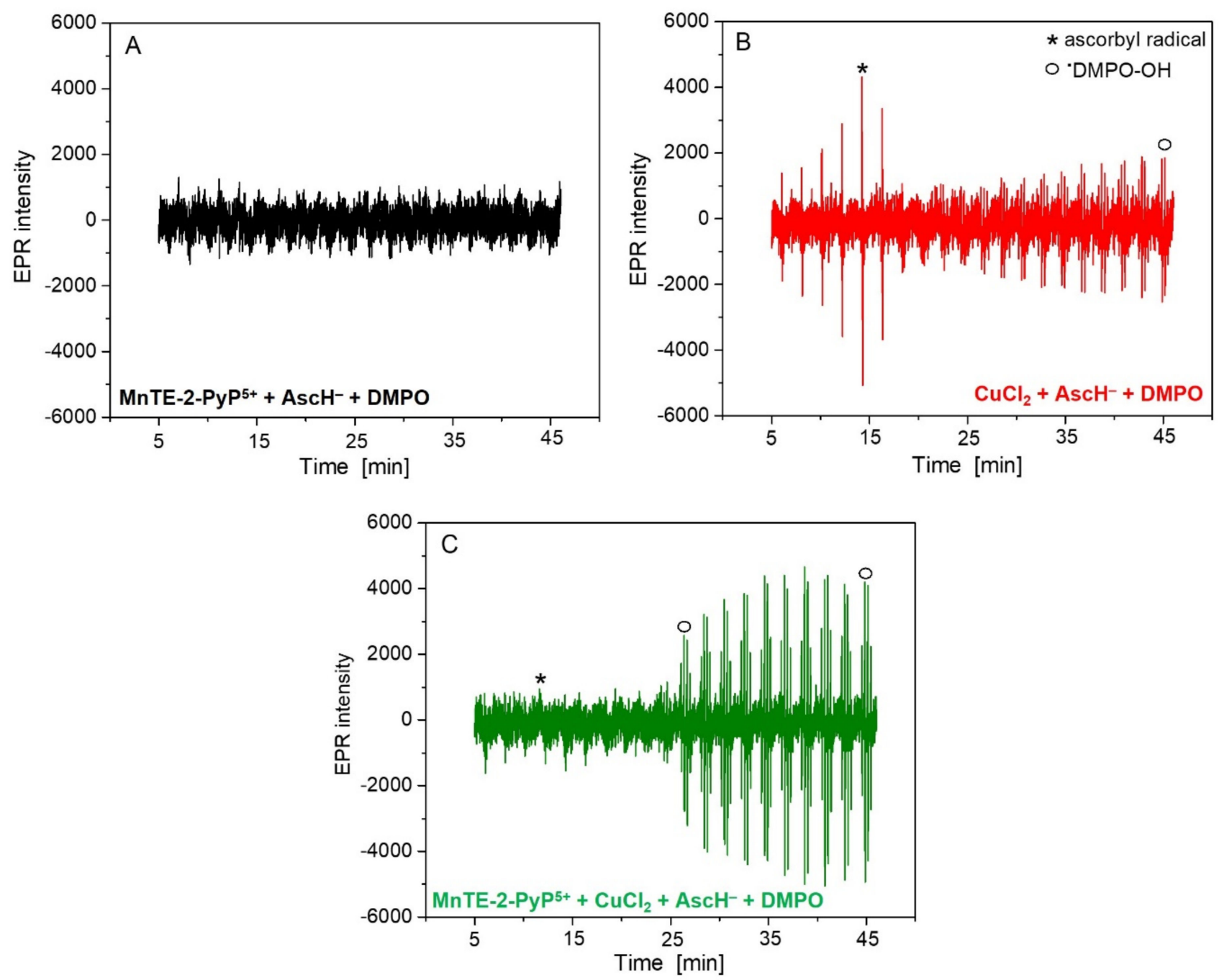

Figure 5. EPR spectra (20 spectra were measured, each consists of 3 scans) measured for (A) System 1, (B) System 2 and (C) System 3 as described in Figure 5. (*-ascorbyl radical, $\bigcirc-{ }^{\bullet} \mathrm{DMPO}-\mathrm{OH}$ adduct).

This unambiguously confirms the enhancement in the production of reactive oxygen species (ROS) in the reaction system containing MnTE-2-PyP ${ }^{5+}$, ascorbate and $\mathrm{Cu}(\mathrm{II})$. Thus, Figure 6A demonstrates that a $\mathrm{MnP} /$ Asc system catalyzes HA degradation. The catalysis is further enhanced in the presence of $\mathrm{Cu}$ (II) within 10 to $30 \mathrm{~min}$ of the main degradation phase (Figure $6 \mathrm{~B}$ ). The initial rates at $20 \mathrm{~min}$ of reaction were calculated from the first derivation of the time-dependent changes in dynamic viscosity $(\eta)$ of the HA solution. The solution comprised MnTE-2-PyP ${ }^{5+}$, and $100 \mu \mathrm{M}$ ascorbate in the absence (see Figure 6C) and presence of $1 \mu \mathrm{M} \mathrm{Cu}$ (II) (see Figure 6D). The corresponding rates at $t=20 \mathrm{~min}$, (defined as $\left.-(\mathrm{d} \eta / \mathrm{d} t)_{t=20}\right)$, are listed in Table 2 . The enhanced production of ROS was further demonstrated by the EPR spin trapping technique for system MnTE-2-PyP ${ }^{5+}+$ $\mathrm{AscH}^{-}+\mathrm{Cu}$ (II) at much lower concentrations of reagents in the presence of HA [20]. 

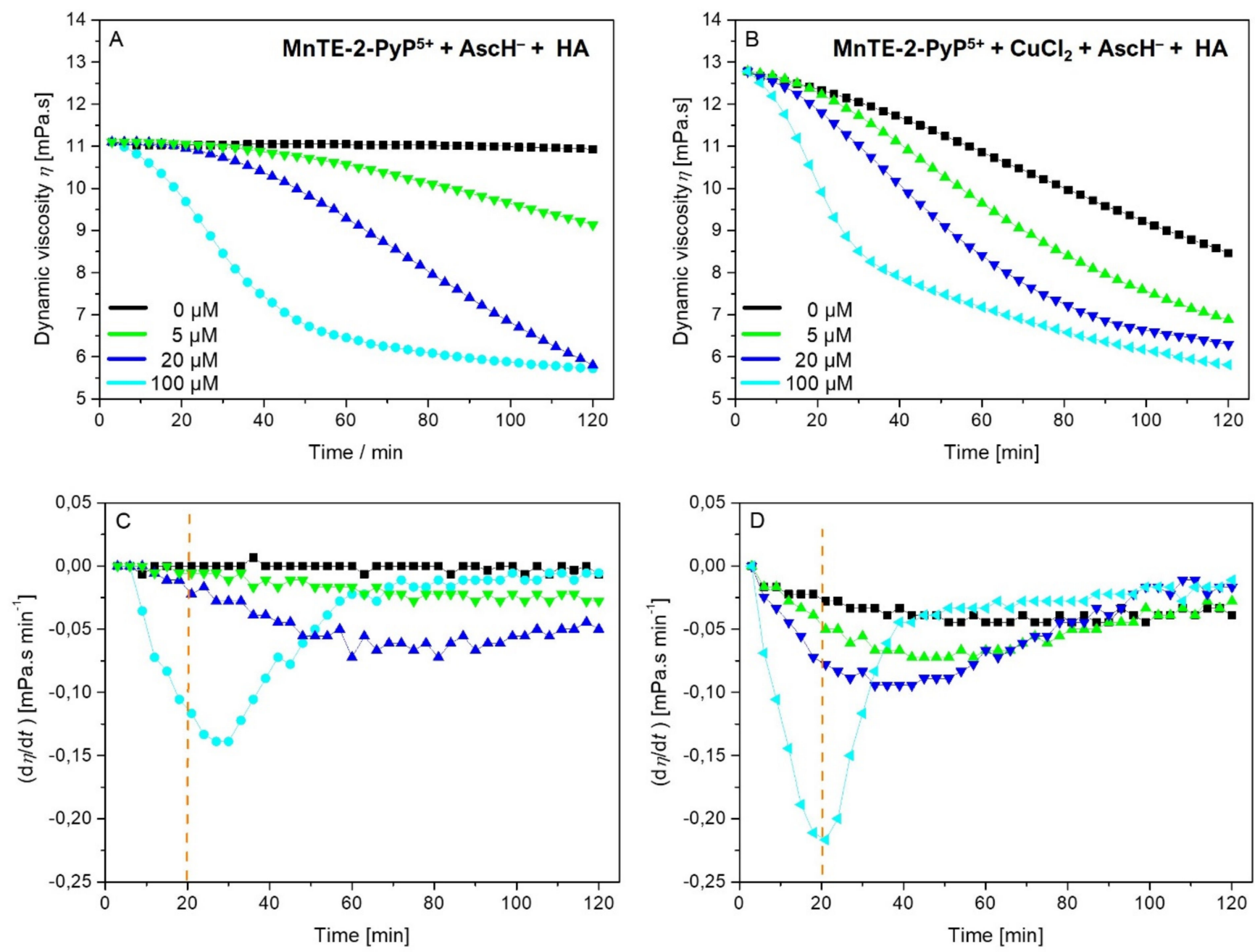

Figure 6. Time-dependent changes in dynamic viscosity $(\eta)$ of the HA solution subjected to MnTE-2-PyP ${ }^{5+}$ at concentrations 0 (black curve), 5 (green curve), 20 (blue curve), and $100 \mu \mathrm{M}$ (cyan curve) and $100 \mu \mathrm{M}$ ascorbate in the absence of $\mathrm{Cu}(\mathrm{II})$ (A) and in the presence of $1 \mu \mathrm{M} \mathrm{Cu}(\mathrm{II})(\mathbf{B})$, as well as the corresponding first derivative curves in time $(\mathrm{d} \eta / \mathrm{d} t=\mathrm{f}(t))$ in the absence of $\mathrm{Cu}$ (II) (C) and in the presence of $1 \mu \mathrm{M} \mathrm{Cu}$ (II) (D). The HA concentration was $1.75 \mathrm{mg} / \mathrm{mL}$.

Table 2. The values of the rates at 20 min of the process of HA degradation, $-(\mathrm{d} \eta / \mathrm{d} t)_{t=20}$ are listed and are derived from the time-dependent changes in dynamic viscosity $(\eta)$ of the HA solution subjected to MnTE-2-PyP ${ }^{5+}$ at different concentrations and $100 \mu \mathrm{M}$ ascorbate in the presence or in the absence of $1 \mu \mathrm{MCu}(\mathrm{II})$. Initial rates, $-(\mathrm{d} \eta / \mathrm{d} t)_{t=0}$ : the rate at $t \sim 0 \mathrm{~min}$.

\begin{tabular}{|c|c|c|c|c|}
\hline & \multicolumn{4}{|c|}{ Rates at $t=20 \mathrm{~min}-(\mathrm{d} \eta / \mathrm{d} t)_{t=20} / \mathrm{mPa} \cdot \mathrm{s} \cdot \mathrm{min}^{-1}$} \\
\hline MnTE-2-PyP ${ }^{5+}$ & $0 \mu \mathrm{M}$ & $5 \mu \mathrm{M}$ & $20 \mu \mathrm{M}$ & $100 \mu \mathrm{M}$ \\
\hline $0 \mu \mathrm{M} \mathrm{Cu}(\mathrm{II})$ & 0 & 0.006 & 0.017 & 0.115 \\
\hline \multirow[t]{2}{*}{$1 \mu \mathrm{M} \mathrm{Cu}(\mathrm{II})$} & 0.020 & 0.045 & 0.075 & 0.215 \\
\hline & \multicolumn{4}{|c|}{ Initial rates at $t \sim 0-(\mathrm{d} \eta / \mathrm{d} t)_{t=0} / \mathrm{mPa} \cdot \mathrm{s} \cdot \mathrm{min}^{-1}$} \\
\hline MnTE-2-PyP $5+$ & $0 \mu \mathrm{M}$ & $5 \mu \mathrm{M}$ & $20 \mu \mathrm{M}$ & $100 \mu \mathrm{M}$ \\
\hline $0 \mu \mathrm{M} \mathrm{Cu}(\mathrm{II})$ & 0 & 0.006 & 0.0331 & 0.0779 \\
\hline
\end{tabular}

The following mechanism, depicted in Scheme 1, for the catalysis of HA degradation was proposed. The redox cycling with ascorbate and oxygen allows ortho isomers to produce $\mathrm{O}_{2}{ }^{\bullet-}$ in the reoxidation step, which would dismutate (through self-dismutation or enzymatically) to $\mathrm{H}_{2} \mathrm{O}_{2}$. The subsequent reaction of $\mathrm{H}_{2} \mathrm{O}_{2}$ with ascorbate-reduced $\mathrm{Cu}(\mathrm{I})$ would give rise to ${ }^{\bullet} \mathrm{OH}$ radical and would cause oxidative degradation of HA (Scheme 1). In such a scenario, ortho Mn porphyrins, by producing the additional amount of $\mathrm{H}_{2} \mathrm{O}_{2}$ and 
in turn ${ }^{\bullet} \mathrm{OH}$ radicals, act as catalysts of $\mathrm{HA}$ oxidative degradation. HA is present at high levels in tumors and is reported to promote carcinogenesis and metastases [17,21]. Our studies taught us that ortho Mn porphyrins are able to promote the HA degradation in the presence of $\mathrm{Cu}$ (II) [or $\mathrm{Fe}(\mathrm{III})]$ and ascorbate. Such knowledge increases our insight into their anticancer therapeutic potential [22-25].

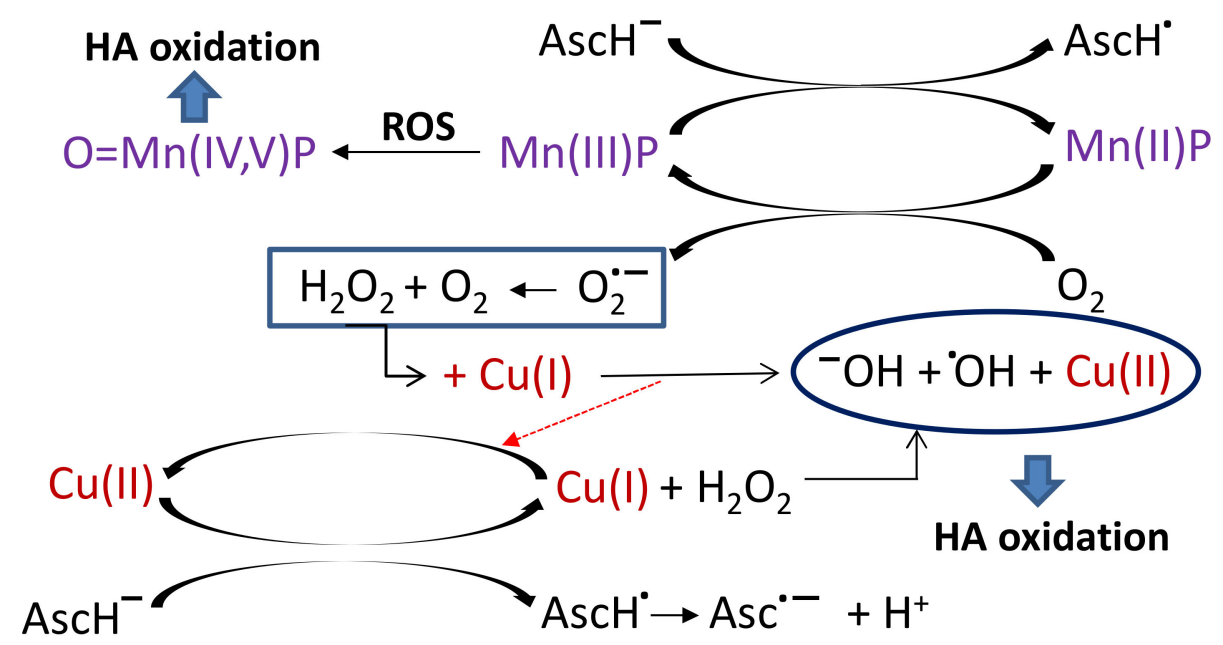

Scheme 1. Proposed mechanism of hyaluronic acid degradation in the presence of ortho isomeric $\mathrm{Mn}(\mathrm{III})$-porphyrins, $\mathrm{Cu}$ (II) and ascorbate giving rise to enhanced production of ${ }^{\bullet} \mathrm{OH}$ radicals and HA oxidation (note that the formation of hydroperoxyl radical $\mathrm{HO}_{2}{ }^{\bullet}$ is valid for acidic environment while at physiological pH 7.8 the superoxide anion dominates. During inflammation, which accompanies cancer, the tissues are in a slightly acidic environment [26]. The bottom part of Scheme 1 represents WBOS.

The participation of transition metals $\mathrm{Cu}(\mathrm{II})$ [or $\mathrm{Fe}(\mathrm{III})]$ in free radical generation in the presence of ascorbate under aerobic conditions is shown by the Haber-Weiss reaction (Equation (1)). In that reaction $\mathrm{O}_{2}{ }^{\bullet-}$ and $\mathrm{H}_{2} \mathrm{O}_{2}$ interact in the presence of transition metal catalysts via the reaction:

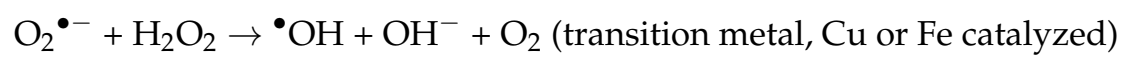

The HA degradation by ${ }^{\bullet} \mathrm{OH}$ radicals, produced in a reaction mixture containing $\mathrm{Cu}(\mathrm{II})$, ascorbate and $\mathrm{Mn}$ porphyrins results in polymer fragments of lower molecular weight $[11,13,20]$ as illustrated in Scheme 2 . This is a consequence of a reaction of hydroxyl radicals with HA forming carbon centered radicals that react with molecular oxygen, resulting in the generation of peroxyl radicals serving as a source of ${ }^{\circ}$ OOA peroxyl radicals and consequently a source of ${ }^{\bullet}$ DMPO-OA adducts in spin trapping studies $[20,27]$.

While the same mechanism as shown in Scheme 1 with regards to ascorbate would operate with both ortho and para isomers, the reduction of para MnTM-4-PyP ${ }^{5+}$ into MnTM$2-\mathrm{PyP}^{4+}$, with ascorbate is not thermodynamically favored due to its more negative $E_{1 / 2}$ for the $\mathrm{Mn}(\mathrm{III}) / \mathrm{Mn}$ (II) redox couple (more than $160 \mathrm{mV}$ ) than that of an ortho analog. It cannot be easily reduced in order to get reoxidized unless ascorbate is in excess (Figure 1). Moreover, the reduced and planar MnTM-4-PyP ${ }^{4+}$ would intercalate into HA which would prevent its reoxidation with oxygen and production of superoxide $/ \mathrm{H}_{2} \mathrm{O}_{2}$ and eventually - $\mathrm{OH}$ radical. Thus, MnTM-4-PyP ${ }^{5+}$ would have not given rise to a significant amount of $\mathrm{H}_{2} \mathrm{O}_{2}$ to allow for $\mathrm{Cu}(\mathrm{I}) / \mathrm{H}_{2} \mathrm{O}_{2}$-driven production of ${ }^{\bullet} \mathrm{OH}$ radical. Indeed, neither enhancement of HA degradation nor generation of ${ }^{\bullet} \mathrm{OH}$ radical was demonstrated (Figure $7 \mathrm{~B}$ ). 

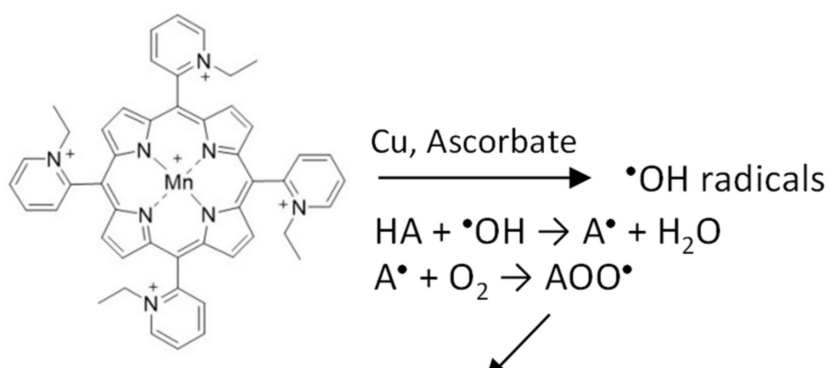

$\mathrm{HA}+\cdot \mathrm{OH} \rightarrow \mathrm{A}^{\bullet}+\mathrm{H}_{2} \mathrm{O}$

$\mathrm{A}^{\bullet}+\mathrm{O}_{2} \rightarrow \mathrm{AOO}^{\bullet}$
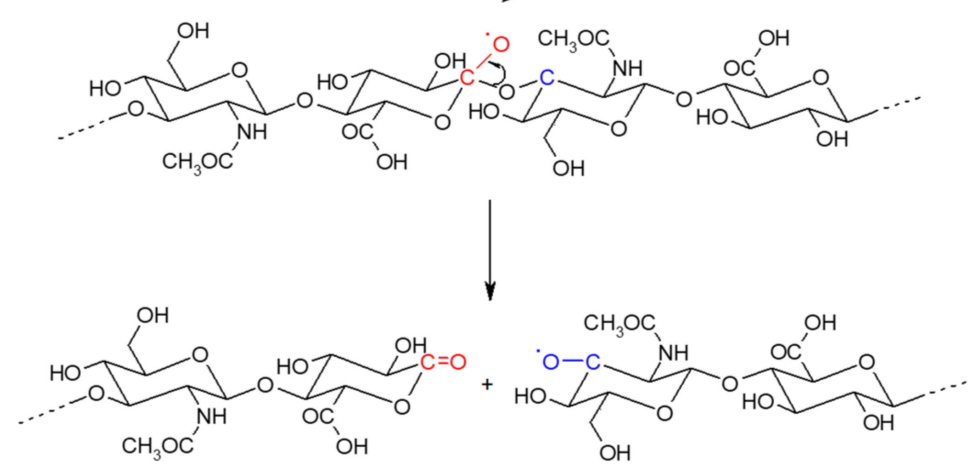

Scheme 2. HA degradation by ${ }^{\bullet} \mathrm{OH}$ radicals, produced in a reaction mixture containing $\mathrm{Cu}(\mathrm{II})$, ascorbate and Mn porphyrins, leading to the polymer fragments of lower molecular weight as e.g., an alkoxy-type macroradical and a HA-like macromolecule bearing a terminal $\mathrm{C}=\mathrm{O}$ group.
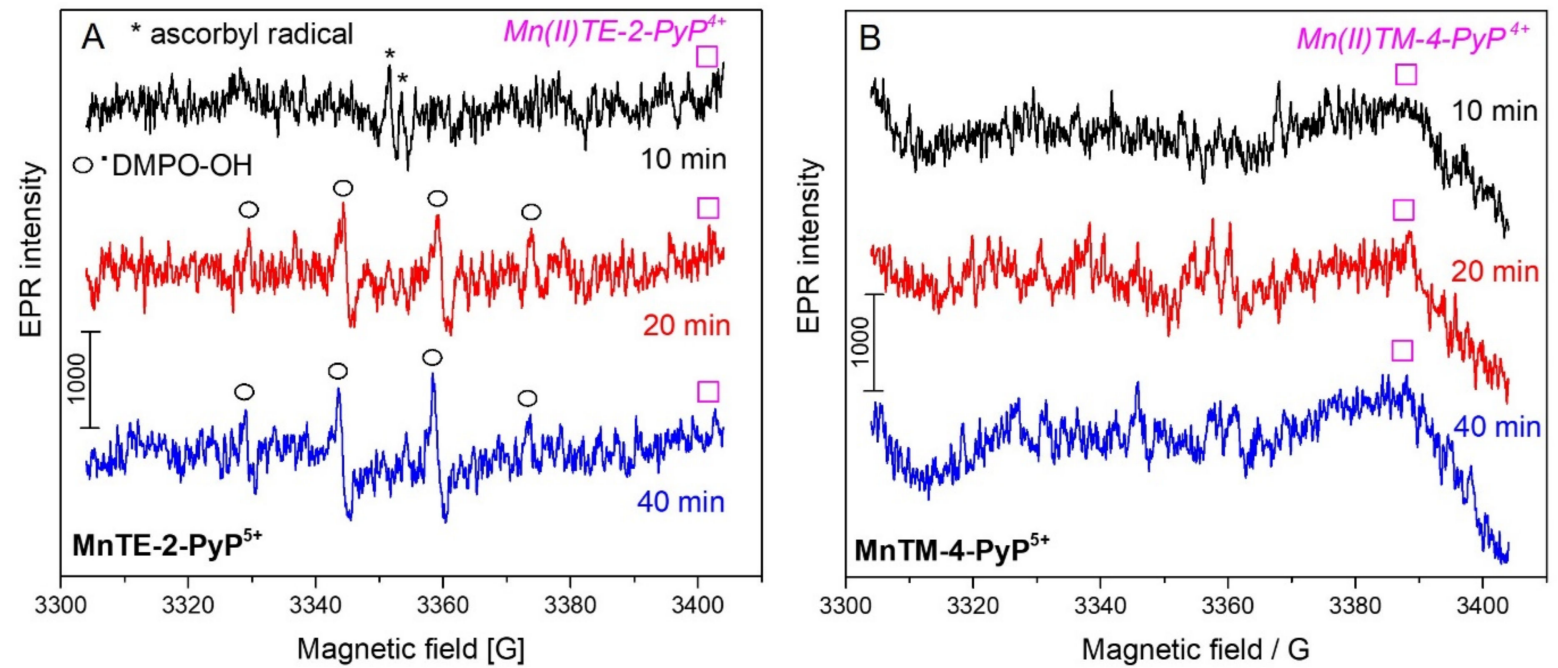

Figure 7. Time evolution of EPR spectra of DMPO spin adducts and of ortho Mn(II)TE-2-PyP4+ (A) and para Mn(II)TM4-PyP ${ }^{4+}(\mathbf{B})$ state in the aqueous solutions saturated with air at room temperature for the system: $250 \mu \mathrm{L}$ water solution

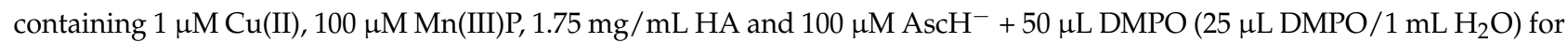
$\mathrm{MnTE}_{-2-\mathrm{PyP}^{5+}}$ (A) and for MnTM-4-PyP ${ }^{5+}$ (B) (*-ascorbyl radical; $\bigcirc-{ }^{*} \mathrm{DMPO}-\mathrm{OH}$ adduct; $\chi$ — signal from Mn(II) state).

With MnTE-2-PyP ${ }^{5+}$, a clear production of ROS was observed in the presence of HA within the first $40 \mathrm{~min}$ (EPR spectra of ${ }^{\circ} \mathrm{DMPO}-\mathrm{OH}$ adducts are marked by circles, Figure 7A). Due to its rapid reoxidation, a significant EPR signal of reduced Mn(II) was not seen (Mn(II) line in Figure 7A). With MnTM-4-PyP ${ }^{5+}$, no ROS formation was observed as a negligible amount of DMPO spin adducts was detected (Figure 7B). Data are in agreement with the differences in kinetics and thermodynamics of the reaction of ortho and para Mn porphyrins with ascorbate and oxygen $[4,19,28]$. MnTE-2-Py $\mathrm{P}^{5+}$ gets readily reduced with ascorbate (see Figure 1) and the reduced Mn(II) cycles back to Mn(III) state (with $k_{\mathrm{ox}}(\mathrm{MnP}) \sim 8 \times 10^{4} \mathrm{M}^{-1} \mathrm{~s}^{-1}$ [28]), while reducing oxygen to the superoxide anion radical (see Scheme 1). 
Moreover, MnTM-4-PyP ${ }^{5+}$ inhibited HA degradation regardless of the time point at which it was added into the $\mathrm{Cu}(\mathrm{II}) /$ ascorbate/HA reaction mixture (see Figure $2 \mathrm{~B}$ ). A small enhancement in HA degradation was seen only when the ascorbate $(100 \mu \mathrm{M})$ was present at a huge excess over MnP (5 $\mathrm{MM})$. Such scenario allowed only for a low extent of MnP reduction and consequently for a very low yield of reoxidation reaction (with $k_{\mathrm{ox}}(\mathrm{MnP})$ $\left.\sim 1.1 \times 10^{6} \mathrm{M}^{-1} \mathrm{~s}^{-1}\right)$.

The behavior of MnTM-4-PyP ${ }^{5+}$ may be explained as follows: as compared to ortho isomer, para MnTM-4-PyP $\mathrm{P}^{5+}$ is a planar molecule. It was reported that, when reduced to MnTM-4-PyP ${ }^{4+}$, it loses axially bound molecules and becomes even more planar and thus intercalates readily into nucleic acids (RNA and DNA) [5]. Axially bound water molecules would have otherwise imposed steric hindrance to intercalation. Such interactions resulted in a loss of its SOD-like activity [5]. Once nucleic acids were removed, the SOD-like activity was restored [5]. It may be thus safely assumed that the planar reduced MnTM4-PyP ${ }^{4+}$ would intercalate into the $\mathrm{HA}$ and stabilize the polymer. Being trapped within the HA polymer, the reduced MnTM-4-PyP ${ }^{4+}$ would not be able to cycle back to Mn(III)P with oxygen in order to give rise to reactive species and degrade HA, despite its faster reoxidation rate with oxygen $\left[k_{o x}(\mathrm{MnP})\right]$ than that of $\mathrm{MnTE}-2 \mathrm{PyP}^{4+}$. It is well known that charge/charge interactions, hydrogen bonding and intercalations have a dramatic impact on the in vivo actions of molecules $[5,29,30]$.

\section{Materials and Methods}

\subsection{Chemicals}

Hyaluronan $\left(\mathrm{M}_{\mathrm{w}}=1.69 \mathrm{MDa}, \mathrm{M}_{\mathrm{w}} / \mathrm{M}_{\mathrm{n}}=1.64\right)$ was obtained from Lifecore Biomedical Inc., Chaska, MN, USA (content of transition metals: copper $<1 \mathrm{ppm}$, iron 6 ppm). $\mathrm{NaCl}$ p.a. and $\mathrm{CuCl}_{2} \cdot 2 \mathrm{H}_{2} \mathrm{O}$ p.a. were purchased from Slavus Ltd., Bratislava, Slovakia. Ascorbic acid used was obtained from Merck KGaA, Darmstadt, Germany. Aqueous solutions of MnTE-2-PyP ${ }^{5+}, 19.6$ mM, MnTnHex-2-PyP ${ }^{5+}, 7.23 \mathrm{mM}$, and MnTnBuOE-2-PyP ${ }^{5+}, 5.69 \mathrm{mM}$ were obtained from Batinic-Haberle's lab, Duke University School of Medicine, North Carolina, USA. MnTM-4-PyP ${ }^{5+}$ was obtained from the University of Aveiro, Aveiro, Portugal and was prepared via alkylation of metal-free ligand followed by its metalation. 5,5-Dimethyl-1-pyrroline $N$-oxide (DMPO, $\geq 97 \%$ ) was purchased from Sigma-Aldrich Chemie $\mathrm{GmbH}$, Steinheim, Germany. Deionised high-purity grade water, with conductivity of $\leq 0.055 \mu \mathrm{S} / \mathrm{cm}$, was made by using the TKA water purification system (Water Purification Systems GmbH, Niederelbert, Germany).

\subsection{Preparation of Stock and Working Solutions}

The HA samples (16 mg) were dissolved in $0.15 \mathrm{M}$ aqueous $\mathrm{NaCl}$ solution for $24 \mathrm{~h}$ in the dark in two steps: first, $4.0 \mathrm{~mL}$ of $0.15 \mathrm{M} \mathrm{NaCl}$ was added to HA swelling and after $6 \mathrm{~h}$, $0.15 \mathrm{M} \mathrm{NaCl}$ in the volumes 3.90, 3.85, 3.79 or $3.76 \mathrm{~mL}$ was added. Ascorbic acid $(16 \mathrm{mM})$ and cupric chloride solutions $(160 \mu \mathrm{M})$ were prepared in $0.15 \mathrm{M}$ aqueous $\mathrm{NaCl}$. Solutions of MnTM-4-PyP ${ }^{5+}$ and MnTE-2-PyP ${ }^{5+}(16 \mathrm{mM})$ were made and diluted to concentrations 3.2 and $0.8 \mathrm{mM}$ in deionized water. Solutions of $\mathrm{MnTnBuOE-2-PyP} \mathrm{P}^{5+}$ and MnTnHex-2-PyP $\mathrm{P}^{5+}$ at concentrations 3.2 and $0.8 \mathrm{mM}$ were made in deionized water. The DMPO solution was prepared by dissolving $25 \mu \mathrm{L}$ of DMPO (distilled prior to the application and stored at $-18{ }^{\circ} \mathrm{C}$ ) in $1 \mathrm{~mL}$ of deionized water.

\subsection{Studies of Inhibition of Hyaluronan Degradation}

The assays used to explore the effect of the MnPs on oxidatively degraded hyaluronan were as follows:

i. A volume of $50 \mu \mathrm{L}$ of $\mathrm{CuCl}_{2}$ solution was added to the HA solution $(7.90,7.85,7.79$ or $7.76 \mathrm{~mL}$ ), and the mixture, after a stirring of $30 \mathrm{~s}$, was left to stand for $7.5 \mathrm{~min}$ at room temperature. Then, the MnP solution $(0,50,110$ or $140 \mu \mathrm{L})$ was added to the reaction mixture, followed by stirring again for $30 \mathrm{~s}$. Finally, $50 \mu \mathrm{L}$ of ascorbic acid solution 
was added to the solution, and the mixture was stirred for another $30 \mathrm{~s}$. The solution was then immediately transferred into the viscometer Teflon ${ }^{\circledR}$ cup reservoir.

ii. In the second experimental design, a procedure similar to that described in (i) was applied; however, after $7.5 \mathrm{~min}$, the $50 \mu \mathrm{L}$ of ascorbic acid solution was added and stirred for $1 \mathrm{~h}$. Then 50,110 or $140 \mu \mathrm{L}$ of the MnP solution was added, followed by stirring for $30 \mathrm{~s}$. The solution mixture was then immediately transferred into the viscometer Teflon ${ }^{\circledR}$ cup reservoir. Dynamic viscosity of the reaction mixture $(8 \mathrm{~mL})$ containing HA $(1.75 \mathrm{mg} / \mathrm{mL})$, ascorbate $(100 \mu \mathrm{M}), \mathrm{Cu}(\mathrm{II})$ ions $(1 \mu \mathrm{M})$ and Mn porphyrins (final concentrations of $0,5,20,100 \mu \mathrm{M})$ was measured by a Brookfield LVDV-II+PRO digital rotational viscometer (Brookfield Engineering Labs., Middleboro, MA, USA) at $25.0 \pm 0.1{ }^{\circ} \mathrm{C}, 180 \mathrm{rpm}$ at a shear rate of $237.6 \mathrm{~s}^{-1}$ for $2 \mathrm{~h}$. All details of how the degradation of HA can be assessed by dynamic viscosity is described in [31].

\subsection{Electron Paramagnetic Resonance (EPR)}

The generation of free radicals during HA degradation was examined by a spin trapping technique in an EPR X-band EMX spectrometer (Bruker, Rheinstetten, Germany) at ambient temperature. The reaction mixture was composed of HA solution $(1.75 \mathrm{mg} / \mathrm{mL})$, $\mathrm{Cu}(\mathrm{II})$ ions $(1.0 \mu \mathrm{M}), \mathrm{MnPs}(100 \mu \mathrm{M})$, and ascorbic acid $(100 \mu \mathrm{M})$. The spectra were recorded at $2,20,60,90$, or $150 \mathrm{~min}$ after the addition of ascorbic acid. Each solution $(250 \mu \mathrm{L})$ was thoroughly stirred with $50 \mu \mathrm{L}$ of $0.212 \mathrm{M}$ DMPO spin trap prior to its insertion in a thin flat EPR quartz cell. The operational parameters of the equipment were adjusted as follows: center field $3354 \mathrm{G}$, sweep width $100 \mathrm{G}$, time constant $81.92 \mathrm{~ms}$, conversion time $20.48 \mathrm{~ms}$, receiver gain $5 \times 10^{5}$, microwave power $10 \mathrm{~mW}$, and modulation amplitude $2 \mathrm{G}$, number of scans from 3 to 20 .

\section{Conclusions}

We have demonstrated herein the enhancement of the $\mathrm{Cu}$ (II)/ascorbate-driven oxidative degradation of hyaluronic acid by redox active cationic ortho isomeric $\mathrm{Mn}(\mathrm{III})$ alkyl-alkoxyalkylpyridylporphyrins, but not by para isomer MnTM-4-Py $\mathrm{P}^{5+}$. Their catalytic abilities or lack thereof are due to the differences in their thermodynamic and kinetic properties. The reduction of para $\mathrm{MnTM}-4-\mathrm{PyP}^{5+}$ with ascorbate is not thermodynamically favored due to its more negative $E_{1 / 2}$ for the $\mathrm{Mn}$ (III)/Mn(II) redox couple than that of an ortho analogs and happens only at sufficient excesses of ascorbate. In turn, no reoxidation of reduced Mn(II)TM-4-PyP ${ }^{4+}$ happens which would have otherwise enabled formation of ${ }^{\bullet} \mathrm{OH}$ radical. Importantly, the planar para $\mathrm{MnTM}-4-\mathrm{Py}^{5+}$ and more so when reduced, intercalates into the HA and stabilizes the polymer. In turn, the strongly intercalated reduced complex within the HA network is not easily accessible to molecular oxygen and remains inactive.

Our data point to another possible in vivo action of Mn porphyrins, commonly known as SOD mimics. Due to the high level of HA in cancer (which seems to promote cancer proliferation and metastases), its oxidative degradation catalyzed by MnPs (in the presence of endogenously available $\mathrm{Cu}$ (II)/ $\mathrm{Fe}$ (III) and ascorbate) may further strengthen the anticancer therapeutic potential of redox active cationic ortho isomeric $\mathrm{Mn}$ (III) $\mathrm{N}$-alkylalkoxyalkylpyridylporphyrins.

Author Contributions: Conceptualization, K.V., I.B.-H. and L.Š.; Investigation, K.V., P.R. and N.M.M.M.; Project administration, P.R.; Supervision, L.Š.; Writing—original draft, K.V. and P.R.; Writing—review \& editing, P.R., I.B.-H. and L.Š. All authors have read and agreed to the published version of the manuscript.

Funding: The study was supported by VEGA grants [2/0019/19] and [1/0504/20]. The authors are grateful to the University of Aveiro and FCT/MCT for the financial support for the LAQV [UIDB/50006/2020]. N.M.M. Moura thanks the FCT/MEC for the individual contract [REF.-048-88ARH/2018]. PR thanks the Slovak Research and Development Agency for financial support under the contract Nos. [APVV-15-0053], [APVV-19-0024] and [DS-FR-19-0035]. I.B.H. acknowledges the continuous support of BioMimetix JV LLC. 
Institutional Review Board Statement: Not applicable.

Informed Consent Statement: Not applicable.

Data Availability Statement: The data used to support the findings of this study are included within the main text.

Conflicts of Interest: I.B.H. and Duke University have patent rights and have licensed technologies to BioMimetix JVLLC. I.B.H. is consultant with BioMimetix Pharmaceutical, JLVVC. Duke University and I.B.H. holds equities in BioMimetix Pharmaceutical JLVVC.

\section{References}

1. Batinic-Haberle, I.; Tovmasyan, A.; Spasojevic, I. Mn porphyrin-based redox-active drugs: Differential effects as cancer therapeutics and protectors of normal tissue against oxidative injury. Antioxid. Redox Signal. 2018, 29, 1691-1724. [CrossRef]

2. Batinic-Haberle, I.; Tome, M.E. Thiol regulation by Mn porphyrins, commonly known as SOD mimics. Redox Biol. 2019, 25, 101139. [CrossRef]

3. Batinic-Haberle, I.; Spasojevic, I. 25 years of development of Mn porphyrins-From SOD mimics to thiol signaling to clinical trials. The story of our life in USA. J. Porphyr. Phthalocya. 2019, 23, 1326-1335. [CrossRef]

4. Batinic-Haberle, I.; Benov, L.; Spasojevic, I.; Hambright, P.; Crumbliss, A.L.; Fridovich, I. The relationship between redox potentials, proton dissociation constants of pyrrolic nitrogens, and in vitro and in vivo superoxide dismutase activities of manganese(III) and iron(III) cationic and anionic porphyrins. Inorg. Chem. 1999, 38, 4011-4022. [CrossRef]

5. Batinic-Haberle, I.; Benov, L.; Spasojevic', I.; Fridovich, I. The ortho effect makes manganese(III) meso-tetrakis-(Nmethylpyridinium-2-yl)porphyrin a powerful and potentially useful superoxide dismutase mimic. J. Biol. Chem. 1998, 273, 24521-24528. [CrossRef] [PubMed]

6. Ferrer-Sueta, G.; Batinic-Haberle, I.; Spasojevic, I.; Fridovich, I.; Radi, R. Catalytic Scavenging of Peroxynitrite by Isomeric Mn(III) N-Methylpyridylporphyrins in the Presence of Reductants. Chem. Res. Toxicol. 1999, 12, 442-449. [CrossRef]

7. Batinic-Haberle, I.; Reboucas, J.S.; Spasojevic, I. Superoxide dismutase mimics: Chemistry, pharmacology, and therapeutic potential. Antioxid. Redox Signal. 2010, 13, 877-918. [CrossRef]

8. Weitner, T.; Kos, I.; Mandić, Z.; Batinić-Haberle, I.; Biruš, M. Acid-base and electrochemical properties of manganese meso(orthoand meta-N-ethylpyridyl)-porphyrins: Voltammetric and chronocoulometric study of protolytic and redox equilibria. Dalton Trans. 2013, 41, 14757-14765. [CrossRef] [PubMed]

9. Yimcharoen, M.; Kittikunnathum, S.; Suknikorn, C.; Nak-on, W.; Yeethong, P.; Anthony, T.G.; Bunpo, P. Effects of ascorbic acid supplementation on oxidative stress markers in healthy women following a single bout of exercise. J. Int. Soc. Sports Nutr. 2019, 16, 1-9. [CrossRef]

10. Pehlivan, F.E. Vitamin C: An antioxidant agent. In Vitamin C; IntechOpen: London, UK, 2017; Chapter 2; pp. $23-35$.

11. Valachova, K.; Topolska, D.; Mendichi, R.; Collins, M.N.; Sasinková, V.; Soltes, L. Hydrogen peroxide generation by the Weissberger biogenic oxidative system during hyaluronan degradation. Carbohydr. Polym. 2016, 148, 189-193. [CrossRef] [PubMed]

12. Phaniendra, A.; Jestadi, D.B.; Periyasamy, L. Free radicals: Properties, sources, targets, and their implication in various diseases. Ind. J. Clin. Biochem. 2015, 30, 11-26. [CrossRef] [PubMed]

13. Valachova, K.; Hrabarova, E.; Priesolova, E.; Nagy, M.; Banasova, M.; Juranek, I.; Soltes, L. Free-radical degradation of highmolecular-weight hyaluronan induced by ascorbate plus cupric ions. Testing of bucillamine and its SA981-metabolite as antioxidants. J. Pharm. Biomed. Anal. 2011, 56, 664-670. [CrossRef]

14. Buffone, A.; Weaver, V.M. Don't sugarcoat it: How glycocalyx composition influences cancer progression. J. Cell Biol. 2020, 219, 1-14. [CrossRef]

15. Lahir, Y.H. Understanding the basic role of glycocalyx during cancer. J. Rad. Cancer Res. 2016, 17, 79-84. [CrossRef]

16. Pardoll, D.M. The blockade of immune checkpoints in cancer immunotherapy. Nat. Rev. Cancer 2012, 12, 252-264. [CrossRef]

17. Mitchell, M.J.; King, M.R. Physical Biology in Cancer. 3. The role of cell glycocalyx in vascular transport of circulating tumor cells. Am. J. Physiol. Cell Physiol. 2014, 306, 89-97. [CrossRef] [PubMed]

18. Soltes, L.; Stankovska, M.; Brezova, V.; Schiller, J.; Arnhold, J.; Kogan, G.; Gemeiner, P. Hyaluronan degradation by copper(II) chloride and ascorbate: Rotational viscometric, EPR spin-trapping, and MALDI-TOF mass spectrometric investigations. Carbohydr. Res. 2006, 341, 2826-2834. [CrossRef]

19. Tovmasyan, A.; Sampaio, R.S.; Boss, M.K.; Bueno-Janice, J.C.; Bader, B.H.; Thomas, M.; Reboucas, J.S.; Orr, M.; Chandler, J.D.; Young-Mi Go, J.M.; et al. Anticancer therapeutic potential of Mn porphyrin/ascorbate system. Free Radic. Biol. Med. 2015, 89, 1231-1247. [CrossRef] [PubMed]

20. Valachova, K.; Rapta, P.; Batinic-Haberle, I.; Soltes, L. Manganese porphyrins as pro-oxidants in high-molar-mass hyaluronan oxidative degradation-possible implications in anticancer effects. In Green Chemistry and Green Engineering. Processing Technologies, Properties and Applications; Kulkarni, S., Rawat, N.K., Haghi, A.K., Eds.; Apple Academic Press: Palm Bay, FL, USA, 2021; Chapter 12; pp. 223-241. 
21. Lokeshwar, V.B.; Mirza, S.; Jordan, A. Targeting hyaluronic acid family for cancer chemoprevention and therapy. Adv. Cancer Res. 2014, 123, 35-65.

22. Batinic-Haberle, I.; Spasojevic, I. Complex chemistry and biology of redox-active compounds, commonly known as SOD mimics, affect their therapeutic effects. Antioxid. Redox Signal. 2014, 20, 2323-2325. [CrossRef] [PubMed]

23. Tong, Q.; Weaver, M.R.; Kosmacek, E.A.; O'Connor, B.P.; Harmacek, L.; Venkataraman, S.; Oberley-Deegan, R.E. MnTE-2-PyP reduces prostate cancer growth and metastasis by suppressing p300 activity and p300/HIF-1/CREB binding to the promoter region of the PAI-1 gene. Free Radic. Biol. Med. 2016, 94, 185-194. [CrossRef]

24. Flórido, A.; Saraiva, N.; Cerqueira, S.; Almeida, N.; Parsons, M.; Batinic-Haberle, I.; Miranda, J.P.; Costa, J.G.; Carrara, G.; Castro, M.; et al. The manganese(III) porphyrin MnTnHex-2-PyP $\mathrm{P}^{5+}$ modulates intracellular ROS and breast cancer cell migration: Impact on doxorubicin-treated cell. Redox Biol. 2019, 20, 367-378. [CrossRef]

25. Batinic-Haberle, I.; Tovmasyan, A.; Huang, Z.; Duan, W.; Du, L.; Siamakpour-Reihani, S.; Cao, Z.; Sheng, H.; Spasojevic, I.; Secord, A.A. $\mathrm{H}_{2} \mathrm{O}_{2}$-driven anticancer activity of $\mathrm{Mn}$ porphyrins and the underlying molecular pathways. Oxid. Med. Cell. Longev. 2021, 2021, 23. [CrossRef] [PubMed]

26. Kato, Y.; Ozawa, S.; Miyamoto, C.; Maehata, Y.; Suzuki, A.; Maeda, T.; Baba, Y. Acidic extracellular microenvironment and cancer. Cancer Cell Int. 2013, 13, 1-8. [CrossRef] [PubMed]

27. Dvoranová, D.; Barbieriková, Z.; Brezová, V. Radical Intermediates in Photoinduced Reactions on TiO 2 (An EPR Spin Trapping Study). Molecules 2014, 19, 17279-17304. [CrossRef] [PubMed]

28. Spasojevic, I.; Batinic-Haberle, I.; Fridovich, I. Nitrosylation of manganese(II) tetrakis(N-ethylpyridinium-2-yl)porphyrin. Nitric Oxide 2000, 4, 526-533. [CrossRef] [PubMed]

29. Bonnesœur, S.; Morin-Grognet, S.; Thoumire, O.; Le Cerf, D.; Boyer, O.; Vannier, J.-P.; Labat, B. Hyaluronan-based hydrogels as versatile tumor-like models: Tunable ECM and stiffness with genipin-crosslinking. J. Biomed. Mat. Res. 2020, 108A, 1256-1268. [CrossRef]

30. Dovedytis, M.; Liu, Z.J.; Bartlett, S. Hyaluronic acid and its biomedical applications: A review. Eng. Regen. 2020, 1, 102-113. [CrossRef]

31. Soltes, L.; Valachova, K.; Mendichi, R.; Kogan, G.; Arnhold, J.; Gemeiner, P. Solution properties of high-molar-mass hyaluronans: The biopolymer degradation by ascorbate. Carbohydr. Res. 2007, 342, 1071-1077. [CrossRef] 